\title{
Heuristic Evaluation of Peruvian Government Web Portals, used within the State of Emergency
}

\author{
Platforms: Aprendo en casa and Covid19-Minsa
}

\author{
Flores Quispe Percy Santiago ${ }^{1}$, Mamani Condori Kevin Alonso ${ }^{2}$ \\ Paniura Huamani Jose Maykol ${ }^{3}$, Anampa Chura Diego David ${ }^{4}$ \\ Richart Smith Escobedo Quispe ${ }^{5}$ \\ Escuela Profesional de Ingeniería de Sistemas \\ Universidad Nacional de San Agustín de Arequipa \\ Perú
}

\begin{abstract}
The development of web platforms is very abundant at present, this event has developed exponentially due to the state of emergency. Therefore, there is a need to evaluate the quality of these platforms to ensure a good user experience, especially if these platforms are governmental. Currently, there are several platforms that have been developed by governments of different nations, which are related to the theme of covid-19; which should be evaluated from a heuristic perspective to detect usability problems that can occur when users interact with a product and identify ways to solve them. This article presents a heuristic evaluation of Peruvian government web portals, used within the state of emergency; for this purpose, a heuristic evaluation is carried out using a list of 15 heuristic principles, proposed by Toni Granollers, from two government platforms: Aprendo en casa and Covid19 Minsa. In this way, it was identified that the Peruvian platform Aprendo en casa has fewer usability problems compared to the Covid19 Minsa platform. Therefore, there is a need to renew or update the Covid19 Minsa platform using the results of the heuristic evaluation performed; on the other hand, although a heuristic evaluation of these Peruvian government platforms is being carried out, it is recommended to continue with a research that uses other usability evaluation methodologies for other platforms of daily use, such as the $\mathrm{S} / \mathbf{3 8 0}$ bonus platform, Bonus for independent or AFP withdrawal.
\end{abstract}

Keywords-heuristic evaluation; usability; heuristic principles; government web portals; Covid-19

\section{INTRODUCTION}

Given the world scenario of 2020 and the current situation that Peru is experiencing in the face of the Covid-19 pandemic, as well as the obvious need to develop web platforms that meet the new requirements that the state needs to address the obvious needs that have arisen because of what happened, such as being able to provide statistical information about the development and growth of the new disease throughout the national territory or being able to carry out distance learning for students of regular basic education in this situation [20], lead us to ask ourselves if these developed platforms comply with the standards of usability that all web applications should comply with, governing us and basing our evaluation on the principles of heuristic evaluation as proposed by Jakob Nielsen's [9].

Being the heuristic evaluation [9] a technique for a faster and less difficult analysis, it can be easily used by any user more than anything else in these times where the increase of users in the network has been increasing massively, to the point that we all depend on different websites to exercise our responsibilities being the state the one that has implemented different websites for the needs of the population that cannot be exercised in person. It could be said that users are becoming more demanding and the needs are increasingly higher, which encourages to evaluate and project a website with an interesting, efficient and convenient format, so Kim demonstrated that there are two criteria to evaluate the interface being the usability and the user experience [18].

The paper to be presented is the production made at the end of the Human Computer Interaction course with motivation in a Human Computer Interaction event at the Catholic University of Santa Maria; which was the motivation to focus on an application. In this way, the proposed paper tries to demonstrate that the heuristic evaluation model, proposed by Toni Granollers [22], meets the basic standards so that any user without previous computational knowledge is able to evaluate web pages identifying general problems compared to other methodologies. For this, the sources in which the development of the paper is supported are reliable; for example: the paper by Toni Granollers, Usability Evaluation with Heuristics, Beyond Nielsen's List [22]; we also rely on quality videos such as the one made by Gonzales, Workshop: Heuristic Usability Evaluation[9], from the Catholic University of Santa Maria. Finally, the expected result is to demonstrate that the Peruvian platform Aprendo en casa has fewer usability problems compared to the Covid19 Minsa platform.

This paper under a methodology uses fourteen heuristics recommended by the literature to perform the evaluation of two important websites especially during the state of emergency for the Peruvian state, allowing to measure the quality of interaction by the interested population, discovering criteria to be considered in the improvement and above all is evidence that developers and designers should consider and not miss.

\section{RELATED WORKS}

Heuristic evaluation is proposed for the identification of usability problems in a web platform which are difficult to see with the naked eye. In the paper by Thewes, Herrmann and Kluge [1] they examine socio-technical systems where they 
prove that the evaluators do not necessarily have to be experts to handle the heuristic test, this is reinforced in the experiment of the authors Paz, Villanueva and Pow [4] who evaluated the HotelClub.com web portal, divided between two novices and three experts, giving results with minimal differences and more specific details on the part of the experts.

On the other hand, Lam and Sajjanhar [3] emphasize the importance of knowing the basics of the topic covered in the web page, making the evaluation more effective. In the research of Botella, Alarcón and Pealver [5] propose a new approach to improve the results of heuristic evaluation done by novices, in addition to the fact that expert evaluators give simple solutions to a recurring problem which are usually not very good contributions. Yusoh and Matayong [6] make use of a public health web portal by surveying the public about usability and evaluated with Jakob Nielsen's 10 heuristic principles which discard 43 sub-factors and prioritize the main usability factors. The wide field of study of heuristic evaluation, can be addressed for web portals, where Borovina, Bošković, Dizdarević, Bulja and Salihbegović described a context of development of the web portal BH Telecom Mobile Services, this same integrates redesign proposals using such evaluation [2].

Likewise, the hotel industry has not received great importance in terms of usability. Yeung and Law present a heuristic evaluation study to calculate usability hazard indices of hotel websites in Hong Kong [7]. Agustinho de Melo and Boaventura-Netto propose a multicriteria evaluation scheme for heuristic algorithms of the classical Condorcet ranking technique. Five criteria and one function were used for natural number ranking. Each algorithm was used with its same structure, applying the same techniques [8]. Thus, the mention of these papers will allow us to have a broad vision to analyze and use new approaches to heuristic evaluation allowing us to make a more effective evaluation of the usability of governmental web portals.

\section{ThEORETICAL FrAME}

\section{A. Usability}

The term usability has several connotations on the part of several authors; for example, from the perspective of Computer Engineering [18], usability refers to the level of usability of a given software product or technological tool; furthermore, Paz [18] maintains that as part of the process of interaction between the user and a computer product, the concept of usability is defined as an indispensable requirement to ensure user satisfaction and a pleasant experience in an environment where labor factors also affect.

On the other hand, usability, according to the ISO 924111 standard, is defined as "the degree to which a product can be used by specific users to achieve specific objectives with effectiveness, efficiency and satisfaction in a specific context of use" [16]. In this sense, the design of the usable interface is closely related to the terms of effectiveness, degree to which the users making use of the product manage to obtain precisely the desired results; efficiency, level of quality of the results achieved by the product in relation to the resources required for its execution, and satisfaction, degree of comfort that the product has on the part of the users after it has been used.
To measure the degree of usability, there are usability evaluation methods, which according to Fernández et al. [17] can be defined as "systematic procedures composed of a series of well-defined activities that allow the collection of data related to the interaction between the end user and the software product, with the purpose of determining how the specific properties of this system contribute to achieving specific user objectives.

It should be noted that there are different taxonomies to classify the usability evaluation methods; in this opportunity we describe the classification according to the type of participants that are required to perform the usability evaluation [18]: First, the Inspection Methods, which involve the participation of specialists in the area of HCI as the heuristic evaluation, the cognitive journey and the review of checklists; second, the Testing Methods, which involve the participation of representative users of the software product to be evaluated, as the tests with users, the pencil and paper test and the co-discovery.

\section{B. Heuristic Evaluation}

In this document, we will go deeper into a usability evaluation method: Heuristic evaluation, according to Sánchez [15] is an evaluation method that aims to measure the quality of an interface so that a group of users can test it in a specific context; therefore, it is carried out by expert juries that make use of inspections based on or guided by previously established principles called heuristics.

On the other hand, heuristic evaluation is a method developed by Jakob Nielsen and Rolf Molich in 1990 to evaluate the level of usability of software products to replace regular user testing [14]; it is important to note that over time, heuristic-based usability evaluation has proven to be an effective method, so there are many studies in the literature that report on its use, especially as part of the process of developing software products [18].

\section{Heuristic Evaluation Method}

There are different lists of principles that can be used for the realization of a heuristic evaluation; for example, [10] the 10 Nielsen heuristic principles, the 8 golden rules of Ben Schneiderman, the checklist of items of Deniese Pierotti, etc. In this opportunity we describe a list of 15 heuristic principles, proposed by Toni Granollers [11], director of the HCI GRIHO research group at the Escuela Politécnica Superior of the University of Lledia, who is also a member of the Association for Human-Computer Interaction (AIPO) and of the Collaborative Network to support teaching-learning processes in the area of Human-Computer Interaction at the Ibero-American level (HCI-collab), the first ten of which are by Nielsen [9]:

1) Visibility and system status: Appropriate information for the user

- Does the application include a title page, section or visible site?

- Does the user always know where he is?

- Does the user always know what the system or application is doing?

- Are the links clearly defined?

- Can all actions be displayed directly? (No other actions required) 
2) Connection between the system and the real world, use of metaphors and human objects: To approach the system with the language of the user but not of the programmer

- Does the information appear in a logical order for the user?

- Does the design of the icons correspond to everyday objects?

- Does each icon do the action you expect?

- Does the system use phrases and concepts familiar to the user?

3) User control and freedom: The user to do and undo system actions.

- Is there a link to return to the initial state or home page?

- Are the "undo" and "redo" functions implemented?

- Is it easy to return to a previous state of the application?

4) Consistency and standards: Maintain a single style on the website and good structure that is attractive to the user

- Do the link tags have the same names as their destinations?

- Do the same actions always have the same results?

- Do icons have the same meaning everywhere?

- Is the information displayed consistently on all pages?

- Are the link colors standard? If not, are they suitable for use?

- Do the navigation elements follow the standards? (Buttons, checkbox, ...)

5) Recognition instead of memory, learning and anticipation: The user can easily identify certain server action.

- Is it easy to use the system for the first time?

- Is it easy to locate information that has already been searched?

- Can you use the system at all times without remembering previous screens?

- Is all the content necessary for navigation or the task on the screen?

- Is the information organized according to a familiar logic to the end?

6) Flexibility and efficiency of use: Facilitate navigation through shortcuts

- Are there keyboard shortcuts for common actions?

- If so, is it clear how to use them?

- Is it possible to easily perform an action that was done before?

- Does the design adapt to changes in screen resolution?

- Is the use of accelerators visible to the normal user?

7) Helps users to recognize, diagnose and redo errors: Validate the error before performing an action.

- Do you show a message before performing irreversible actions?

- Are errors displayed in real time?

- Is the error message easy to interpret?

- Is any code also used to refer to the error?

8) Error prevention: Communicate errors and propose a possible solution to users.

- Does a confirmation message appear before the action is taken?

- Is it clear what information should be entered in each box of a form?
- Does the search engine tolerate typographical and spelling errors?

9) Aesthetic and minimalist design: Highlighting the important:

- Is a design without information redundancy used?

- Is the information brief, concise and accurate?

- Is every piece of information different from the rest and not confused?

- Is the text well organized, with short sentences and quick interpretation?

10) Help and documentation: The system offers relevant help that is easy to search.

- Is there a "help" option?

- If so, is it visible and easily accessible?

- Is the help section aimed at solving problems?

- Is there a FAQ section?

- Is the help documentation clear, with examples?

It also takes into consideration the principles of interaction design being the author Bruce Tognazzini who makes a proposal of 16 principles in which for this heuristic evaluation Granollers makes mention of 5 which will be a complement for a better evaluation [10]:

11) Save the status and protect the work: All information must be auto saved whenever the client wishes which will be stored in the server having the freedom to disconnect and be able to reconnect in another place.

- Can users continue from a previous state (where they had been or from another device)?

- Is "AutoSave" implemented?

- Does the system have a good response to external failures? (Power failure, Internet not working, ...)

12) Color and readability: High contrast text: ideally black on white. Readable font sizes.

- Are the fonts properly sized?

- Do the fonts use colors with enough contrast to the background?

- Do the images or background patterns allow the content to be read?

- Do you consider people with reduced vision?

13) Autonomy Controlled freedom to the user: Being the users who are informed about the state of the system while the administrators manage their variables.

- Do you keep the user informed of the status of the system?

- Also, is the system status visible and updated?

- Can the user make his own decisions? (Personalization)

14) Default values: Easy detection of user defects and easy correction

- Does the system or device offer the option to return to factory settings?

- If so, does it clearly indicate the consequences of the action?

- Is the term "default" used?

15) Latency reduction: Elimination of load states

- Is the execution of the heavy work transparent to the user?

- While performing heavy tasks, is the remaining time or any animation shown? 
To obtain an accurate answer and an appropriate score for the web pages we will analyze each question in each section of the heuristic evaluation, a score will be given with respect to the four options observed in Table I that the evaluator must mark and thus organize the data in a better way.

TABLE I. SCORING ACCORDING TO OPTION CHOSEN BY THE EVALUATOR.

\begin{tabular}{|c|c|}
\hline Options & Score \\
\hline Yes & 1 point \\
\hline Neither yes, nor no & 0.5 points \\
\hline No & 0 points \\
\hline Not applicable & \\
\hline
\end{tabular}

\section{Methodology}

A study [12] has shown that this technique produces results comparable to a laboratory test of the same application. While this technique potentially saves some travel and installation costs, it is still a time- and labor-intensive task, as well as processes, with observers involved full-time for each test and user session.

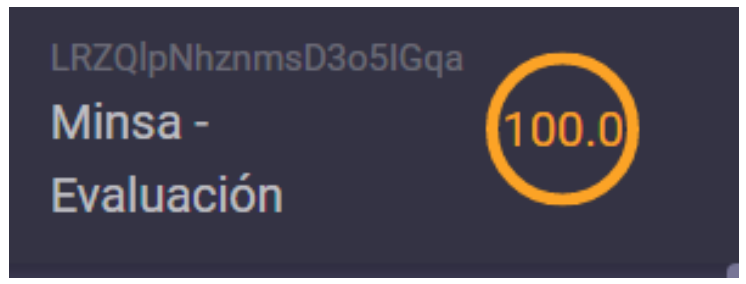

Fig. 1. Pie Chart of Real-time Survey Progress.

Likewise, there is a platform to adequately perform the usability evaluation. This is called Remote Testing Lab. In the same way, usability tests could be carried out. For example, Vividence Corporation [13] offers a type of remote usability test in which test users must download and use an instrumented browser that can capture user click streams, as well as screen shots, and transmit them to the host site for analysis.

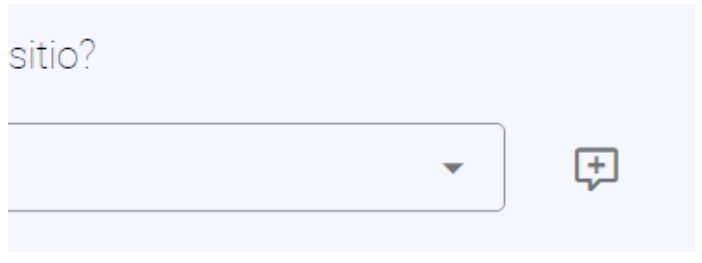

Fig. 2. Adding Comment to Question.

One of the main features of the tool is the percentage of progress shown in the upper right hand side, which is in real time and you can check which sections have been advanced and in percentages, as shown in Fig. 1. Also, the comment option is very useful due to the ambiguity of some questions, which can clarify some answers by the user (Fig. 2).

The platform has a suitable interface for easy user understanding. Within this, the percentage of evaluation that is carried out in real time stands out, showing a small pie chart in the upper left part; in the same way, there is the internationalization, with three languages: Spanish, English

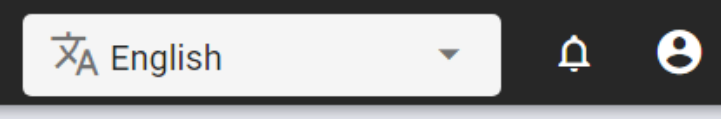

Fig. 3. Language, Notifications and Profile.

and Portuguese (Fig. 3); besides allowing to receive comments from the respondent in each question of each item. Also, a notification icon is shown to inform about some news from the person in charge; and finally, to register the answer, there is a pop-up in the lower right side with the options to save and send, which disappears once the survey is finished (Fig. 4).

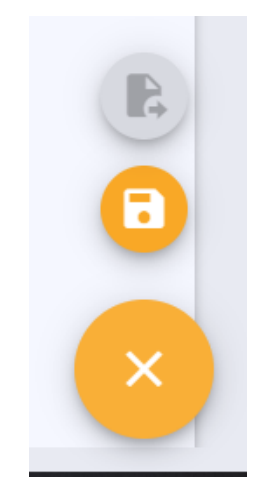

Fig. 4. Save and Send Option.

Finally, the tool has striking transitions for the user, which is complemented by the ease of understanding of the platform. The colors, the font size, among other aspects help the permanent attention of the user.

\section{Government Platforms}

The two case studies chosen for this article were selected from different websites that had purposes such as providing information about bonuses for self-employed workers, withdrawing AFP funds, applying for a work or transit pass, official statistics on infections according to the Minsa, infected areas in Peru, self-testing by the Covid-19 of both the Minsa and the medical school, access to virtual classrooms, and coronavirus results [19].Among all these web pages with different purposes, we have selected and seen the importance of making a heuristic evaluation of two of them.

First of all, we have Aprendo en casa, a website created in this pandemic to continue with basic and regular education through virtual classes, the importance and the challenge that this website has is colossal according to Eduardo Leon, since the public school in its face-to-face mode has failed to teach children to read and write and to be able to carry out this education from a distance poses a great challenge [20], the same author of the commentary tells us that this website focuses all its offerings on the written text, which for the student represents a great barrier, apart from the fact that he also mentions that many of his workbooks do not respond to the logic of distance education, seen already one of the many problems that this page presents and the great challenge that it supposes we have seen convenient to take it as a case study for our heuristic evaluation, since to better fulfill its purpose 
it will have to possess a good user interface and adequate for the people that it is directed as the children are.

On the other hand, we have the Minsa's Covid-19 infection statistics website, which is of great importance in the current pandemic, since it fulfills the important function of informing the population of the progress of the disease in Peru in terms of those infected at the national and regional level, the number of tests performed, including rapid and molecular tests, the number of deaths from the disease, the mortality rate, hospitalizations, and the availability of ICU beds, among others [21]. In view of all the functions that this website should have and its importance, we have found it convenient to carry out a heuristic evaluation of the website, since the level of usability will determine, to a certain extent, how well a user can navigate to get information on this page.

\section{RESUlTS}

The evaluation of the Aprendo en Casa and Covid19Minsa platforms has been carried out by the authors of this article; it is worth mentioning that for this purpose the platform described in the Methodology section is used, within the Theoretical framework. For this, the four evaluators, before starting the evaluation of the platforms had an interaction with these platforms of a duration of 10 minutes.

Fig. 5 and Fig. 7, show the final scores of all evaluators for each principle (this is shown in the Answers section of Remote Testing Lab. In this table, the important values are those in the second column, where the usability percentages are stored. Analyzing these results, it can be seen that, in general, the Aprendo en Casa web platform has a good level of usability.

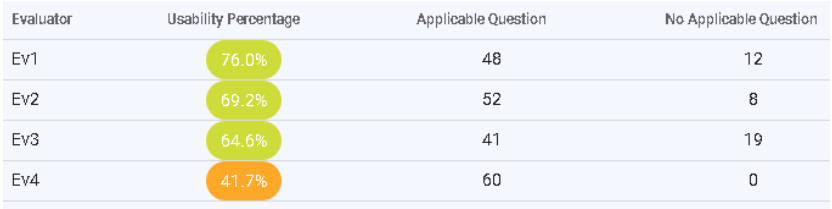

Fig. 5. Final Scores of the I Learn at Home Platform Evaluation

On the other hand, Fig. 6 summarizes all the evaluations, showing the average of all the evaluations, which is $62.9 \%$, which means a slightly good level of usability; it is worth noting that when analyzing each principle, it can be seen that the principles " 11 - Save the state and protect the work", "14 - Default values" and "15 - Reduction of latency" show the lowest values; then, it is concluded that the aspects already mentioned should be improved.
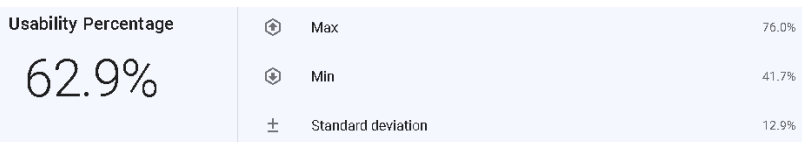

$41.7 \%$

Fig. 6. Average Final Scores of the I Learn at Home Platform Evaluation.

On the other hand, in the Covid19-Minsa platform we can see as shown in Fig. 8 and Fig. 10 the final scores of the evaluators for each principle where analyzing the results we can say that the COVID19-Minsa platform has a level of usability above $50 \%$.

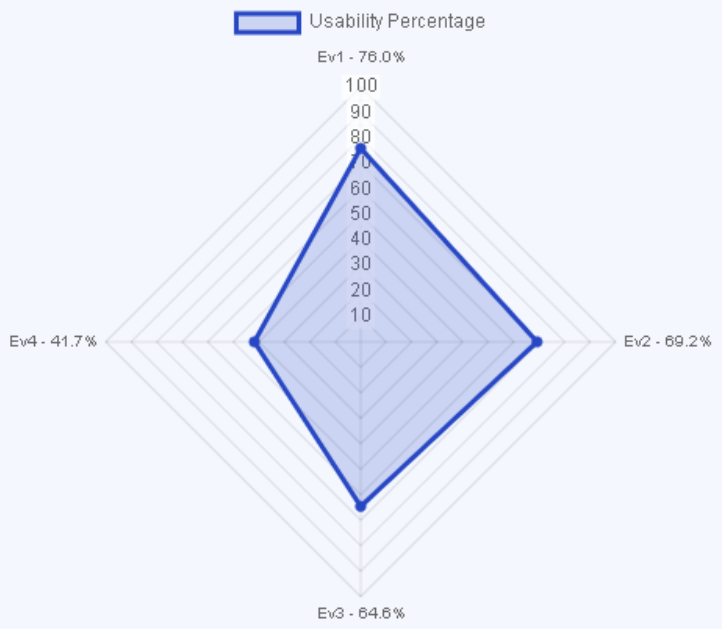

Fig. 7. Final Score Chart for the I Learn at Home Platform Evaluation.

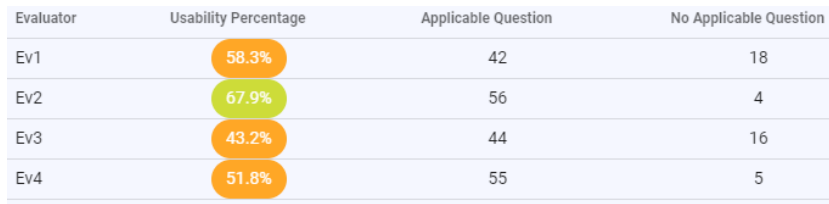

Fig. 8. Final Scores of the COVID19-Minsa Platform Evaluation.

Fig. 9 summarizes all the evaluations, showing the average of all the evaluations, which is $55.3 \%$, which means a level of usability neither so good nor so bad; it is worth noting that when analyzing each principle, it can be seen that the principles "11 - Save the state and protect the work", "13 Autonomy" and "14 - Default values" show the lowest values; then, it is concluded that the aspects already mentioned should be improved.

$$
\begin{array}{ll}
\text { Usability Percentage } & \text { Max } \\
55.3 \% & \text { (4) } \\
& \pm \text { in }
\end{array}
$$

Fig. 9. Average Final Scores of the COVID19-Minsa Platform Evaluation.

\section{CONCLUSIONS}

Using the proposed methodology, it was identified that the Peruvian platform Aprendo en casa presents less of a usability problem compared to the COVID-19-Minsa platform. Therefore, it is necessary to renew or update the COVID-19Minsa platform using the results of the heuristic evaluation carried out, identifying the critical points or making a report on the problems presented by the page and send it directly to the administrators of the same.

Furthermore, it is demonstrated that the heuristic evaluation model, proposed by Toni Granollers, meets the basic standards so that any user without previous computer knowledge is able to evaluate web pages by identifying general problems in comparison with other methodologies. 


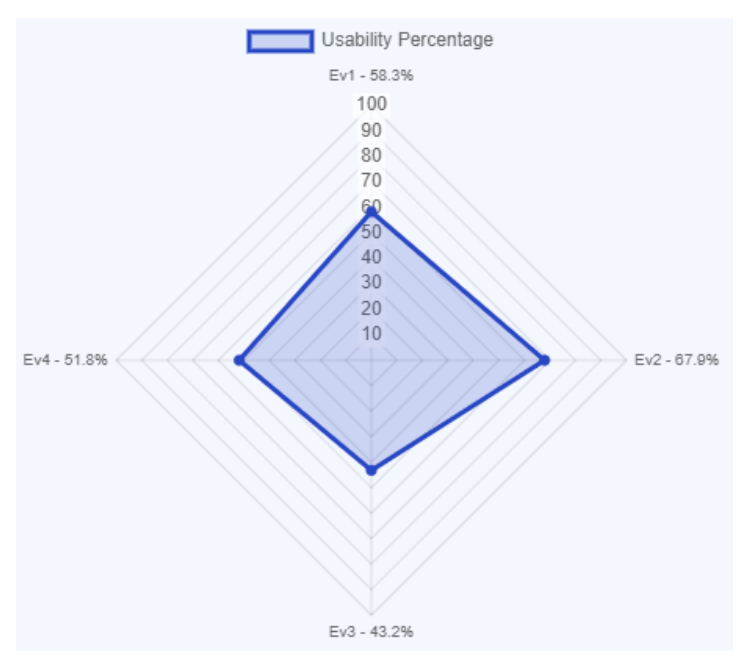

Fig. 10. COVID19-Minsa Platform Evaluation Final Score Chart.

On the other hand, given the existence of several methodologies for the heuristic evaluation of a web page interface, then it is proposed as a possible continuation of the research approach the implementation of other types of methodologies. On the other hand, during the development of the research, although a heuristic evaluation of the Peruvian government platforms, Aprendo en Casa and Covid19-Minsa, is carried out, it is recommended to continue with a research that evaluates other platforms that are used continuously, such as the S/ 380 bonus platform, Bonus for independent or AFP funds withdrawal, which could be the object of another research or be acquired later as an option for other researchers who wish to evaluate the mentioned platforms.

\section{REFERENCES}

[1] F. Thewes, T. Herrmann, and A. Kluge, "Validating a Heuristic Evaluation Method An Application Tes", In Proceedings of Mensch und Computer 2019, pp. 593-597, doi: 10.1145/3340764.3344465

[2] N. Borovina, D. Bošković, J. Dizdarević, K. Bulja and A. Salihbegović, "Heuristic based evaluation of mobile services web portal usability", 2014 22nd Telecommunications Forum Telfor (TELFOR), pp. 11501153, doi: 10.1109 / TELFOR.2014.7034611

[3] D. Lam and A. Sajjanhar, "Heuristic Evaluations of Cultural Heritage Websites," 2018 Digital Image Computing: Techniques and Applications (DICTA), Canberra, Australia, 2018, pp. 1-6, doi: 10.1109/DICTA.2018.8615847.

[4] F. Paz, F. A. Paz, D. Villanueva and J. A. Pow-Sang, "Heuristic Evaluation as a Complement to Usability Testing: A Case Study in Web Domain," 2015 12th International Conference on Information Technology - New Generations, Las Vegas, NV, 2015, pp. 546-551, doi: 10.1109/ITNG.2015.92

[5] F. Botella, E. Alarcon, and A. Palver, "A new proposal for improving heuristic evaluation reports performed by novice evaluators," ACM Int Conf. Proceeding Ser., pp. 72-75, 2013, doi: 10.1145/2535597.2535601

[6] S. Yusoh and S. Matayong, "Heuristic evaluation of online satisfaction survey system for public healthcare service: Applying analytical hierarchical process," Proc. - 2017 2nd Int. Conf. Inf. Technol. Inf. Syst. Electr. Eng. ICITISEE 2017, vol. 2018-January, pp. 462-467, 2018, doi: 10.1109/ICITISEE.2017.8285551
[7] T. Au Yeung, R. Law, "Extending the modified heuristic usability evaluation technique to chain and independent hotel websites," 2014 Associate Professor of Information Technology at the School of Hotel \& Tourism Management, USA, 2016, pp. 1-14, doi: 10.1016/j.ijhm.2003.03.001

[8] V. Agustinho de Melo, P. O. Boaventura-Netto, "METAHEURISTICS EVALUATION: A PROPOSAL FOR A MULTICRITERIA METHODOLOGY," 2015 ACOPPE/Programa de Engenharia de Produção, Universidade Federal do Rio de Janeiro, RJ, Brasil, 2017, pp. 1-5, doi: 10.1590/0101-7438.2015.035.03.0539

[9] T. Granollers. M. Gonzales. (2020, Sep. 20) Taller: Evaluación de usabilidad heurística Available [Video]: https://www.youtube.com/watch?v=YAwrCpVaw6I\&t=15s

[10] Galinus. (2012, Feb. 2) Principios de diseño de interacción de Bruce Tognazzini [Online]. Available: https://usabilidadcss.wordpress.com/2012/02/02/principios-disenointeraccion-bruce-tognazzini/

[11] T. Granollers (2018, abr. 20) Evaluacion heuristica, «beyond Nielsen heuristics $\gg$ [Online]: https://mpiua.invid.udl.cat/evaluacion-heuristicauna-nueva-propuesta/

[12] Hartson, H. R., Castillo, J. C., Kelso, J., and Neale, W. C. Remote evaluation: The network as an extension of the laboratory. Proceedings of CHI'96 Conference, pp. 228-235.

[13] Vividence Corporation, 1850 Gateway Drive, San Mateo, CA. http://www.vividence.com.

[14] Nielsen, J. and Molich, R., 1990. Heuristic evaluation of user interfaces. Presented at the Proceedings of the SIGCHI Conference on Human Factors in Computing Systems, Seattle, Washington, USA.

[15] Sánchez Alvarez, J., Zapata Jaramillo, C. and Jiménez Builes, J., 2017. Evaluación heurística de la usabilidad de software para facilitar el uso del computador a personas en situación de discapacidad motriz. Revista EIA, [online] 14(27), pp.63-72. Available at:ihttp://www.scielo.org.co/scielo.php?script=sci_arttext\&pid=S179412372017000100006\&lang=es; [Accessed 20 November 2020].

[16] Ergonomic requirements for office work with visual display terminals (VDTs). Geneva: ISO, 1998, p. 44.

[17] Fernandez, A., Insfran, E. and Abrahão, S., 2011. Usability evaluation methods for the web: A systematic mapping study, Information and Software Technology, vol. 53, pp. 789-817.

[18] Paz Espinoza, F., 2017. Método para la evaluación de usabilidad de sitios web transaccionales basado en el proceso de inspección heurística. Doctorado. Pontificia Universidad Católica del Perú.

[19] D. Ayma, "Coronavirus en Perú: COVID-19: Estas son las 15 plataformas web que debes conocer para afrontar el estado de emergencia," RPP, 24-Apr-2020. [Online]. Available: https://rpp.pe/politica/gobierno/coronavirus-en-peru-covid-19-estasson-las-15-plataformas-web-que-debes-conocer-para-afrontar-el-estadode-emergencia-noticia-1260604?ref=rpp. [Accessed: 22-Nov-2020].

[20] E. L. Zamora, E. León, and Z. - Educacción, "Evaluación de sistema, alfabetización inicial y 'Aprendo en casa,", Educaccionperu.Org, pp. 1-9, 1972, [Online]. Available: www.educaccionperu.orgdialogoinformadosobrepoliticaspublicashttps:// www.educaccionperu.org.

[21] Covid19.minsa.gob.pe. 2020. Covid 19 En El Perú - Ministerio Del Salud. [online] Available at: https://covid19.minsa.gob.pe/sala_situacional.aspi [Accessed 22 November 2020].

[22] T. Granollers. M. Gonzales (2018) Usability Evaluation with Heuristics, Beyond Nielsen's List [Artículo]: https://www.thinkmind.org/index.php?view=article \&articleid=achi_2018_ 4_10_20055 